\title{
Reducing Stress in Mental Health Practitioners - Becoming Change Agents in Practice Through Action Research
}

\author{
Eileen Petrie \\ La Trobe University \\ Australia
}

\section{Introduction}

The social phenomenon of stress and workplace burnout has spanned over five decades. Despite a plethora of literature that exists, there still remain problematic issues that neither scientific investigation or government legislation has been able to resolve. The literature examined throughout this chapter reflects this 50-year period. It demonstrates that studies into this phenomenon have attempted to define stress, identify causal factors of workplace stress, workplace burnout and environmental congruence; and discusses strategies (focused on both the individual and organizational levels) that have been implemented to effect beneficial outcomes for individuals affected by any one of these.

As this chapter continues, the more recent literature gives a greater recognition to violence in the workplace and legislative enactments as preventative measures to reduce the heavy burden of costs, both physical and financial, to organizations. This review indicates no answer to the problem has been identified to date and that this phenomenon remains, giving a clear indication that further scientific investigation is required to find a solution to what was described as the most serious health issue of the 20th century. Whilst there is a formal literature review presented in this chapter, there is a significant amount of literature support embedded into the various stages of the research study.

This chapter will discuss the issues of stress in a rural remote Community Mental Health Team (CMHT)'s realm of practice and examine a research study that led to a conceptual model of practice in changing praxis. The contribution of this study to the nursing profession is demonstrated through its potential to enhance community nursing practice to deliver effective holistic nursing care to consumers with mental health issues whilst maintaining their own psychological and physical wellness. The specified learnings from this research were envisaged to be processes and strategies for employees to overcome the debilitating effects of stress leading to workplace burnout.

\section{Literature review}

It is well established that CMHT's in rural and remote areas of Australia face issues and constraints specific to their locations relating to distance, population size and recruitment 
and retention of appropriately experienced and skilled staff (Bushy, 2004; Gibb, 2003). The rural remote CMHT nurse's work is influenced not only by the reduced resources but by the diverse and demanding role of first line managers of care for mental health consumers in the geographically challenging setting (Francis \& Chapman, 2008). Further contributing to their workloads, CMHTs extend their case management by maintaining mental health services to the general community. These teams are required to provide flexible and innovative programme development in preventing illnesses and planning of treatment approaches for a comprehensive network of services to meet the ever-changing needs of the general population (Croll, 1997; Gibb, 2003; King, 2001). Lack of resources requires the community nurse to become extremely innovative and creative, with improvisation an important learned skill (Lauder, Reynolds, Reilly \& Angus, 2001). These issues are coupled with an increased demand for their services due to an agricultural crisis that, according to some researchers, Australia has been facing for some decades (Bryant, 1992; Fraser at al., 2002). This agricultural crisis has resulted from the decline in wealth in the agricultural sector (following several years of low rainfall and declining produce and stock prices), and the rationalization of government and private sector services that has led to a decline in the financial well-being of rural towns.

The provision of appropriate mental health services is hindered considerably in rural and remote regions. Isolation is a contributing factor in poor recruitment and retention of qualified staff. Health professionals without mental health qualifications, limited or no access to local mental health services and, scarce and scattered resources inhibit the provision of adequate mental health services to the mental health consumer. Changes in the provision of psychiatric care have occurred on a global scale; many countries have trialled various models of care. In recent years, there has been a shift to providing support for these clinicians through the introduction of mental health nurses and other mental health professionals into general health care teams as supporters, educators and advisors.

However, these initiatives are rarely feasible in rural and remote health care settings due to low staff numbers, large distances involved in accessing specialists, and the time taken to transfer patients from rural regions to regional centres. Therefore, nurses in the rural remote setting are more likely to be exposed to stress, as they may be required to work-without substantive education and training and with limited access to specialist services - with patients with mental health issues. Population models for mental health across Australia proposing links between population or public health and integration with personal health care have, to date, become the chief focus in many community mental health settings (Judd \& Humphreys, 2001). One model proposes assessments, formulation of interventions from prevention to treatment and maintenance at both population and individual levels. It addresses the issues across the lifespan applying to special populations, culturally and linguistically diverse backgrounds, and Aboriginal and Torres Strait Islander peoples. This model serves to provide for a comprehensive, evidence based and cohesive approach toward the provision of optimum mental health care, lessening the extent and burdens of mental disorders affecting populations (Bushy, 2004).

The model is conceptualized at different levels of care incorporating primary, secondary and tertiary mental health care, applying these across the population matrices of the various groups. Implementation of this model requires the identification of input outcomes (treatment outcome is the effect on a patient's health attributable to an intervention), data 
and information system infrastructure, workforce, education and training, research and development, quality processes, resource frameworks and review and change processes (Bushy, 2004).

To achieve the improvement in mental health services that lessens the disease burden, proactive interventions must be implemented to impact effectively on relevant factors at both population and individual levels. These programmes open to the community, total accountability in mental health service provision (Judd \& Humphreys, 2001). However, in attempting to achieve this idealistic approach in maintaining mental health, a time constraint dilemma exists. It becomes imperative for members of CMHTs to allocate a time frame to provide the mental health intervention while maintaining best practice (Pinikahana \& Happell, 2004). The flow-on from this is seen in the detraction from face to face contact and implementation of strategies and interventions to the clients they serve. This has seen an over-extension of personal resources creating a state of constant and unresolved stress for these team members (Pinikahana \& Happell, 2004).

The social phenomenon of stress and workplace burnout has spanned over several decades. Despite a plethora of literature that exists, there still remain problematic issues that neither scientific investigation or government legislation has been able to resolve. The more recent literature gives a greater recognition to violence in the workplace and legislative enactments as preventative measures to reduce the heavy burden of costs, both physical and financial, to organizations. An extensive literature review indicated no answer to the problem has been identified to date and that this phenomenon remains, giving a clear indication that further scientific investigation is required to find a solution to what was described as the most serious health issue of the 20th century. Based on the literature examined this health issue has now gone well beyond the 20th century, giving relevance to the research study.

The study of stress has become an important area of study, as suggested in literature, due to its heavy costs in terms of the damage it has caused within society; to individuals, to relationships and to organizations (Snow, 2006). For the individual physical symptoms associated with work-related stress can include depression, anxiety, feelings of being overwhelmed and inability to cope, decreased work performance, increased sick days and absenteeism, sleeping difficulties such as insomnia, cognitive difficulties such as reduced ability to concentrate or make decisions, fatigue, headaches, heart palpitations, gastrointestinal upsets, such as diarrhoea or constipation, and increased aggression (Caufield et al., 2004; Constantini et al. 1997; Duquette et al., 1994; Johnson \& Preston, 2001).

\section{The impact of stress}

Stress exists in all human beings and is evident in all human beings in varying degrees. Thought to be a strong motivating force, stress is required to produce optimum functioning levels. It stimulates individuals into a response to define and cope with any given situation or problem (stressor) (Lazarus \& Folkman, 1984). This is known as eustress (healthy stress). Excessive and unrelenting stress becomes distress (unhealthy stress) impacting on and reducing work performances. The level of stress felt by an individual is determined by his/her response to a particular situation. If an individual recognizes that he/she is vulnerable when faced with situations perceived to be stressful, the basic human instinct is fight or flight (Seyle, 1956; 1974; 1976). The effects of stress may vary from one individual to 
another with different degrees of intensity. This will impact on the homeostasis of each individual, and the adaptation to this stress will be determined by the effectiveness of his/her own coping mechanisms. Distress results when the demands of the situation exceed the person's ability to cope, or become an unconscious threat to his/her psyche. This phenomenon has been the subject of scrutiny for several decades, with Selye (1956) first proposing a link between stress and health problems in his General Adaptation Syndrome (Kenny, 2000). At times, stressors may become excessive and effective coping mechanisms that may have previously worked are no longer adequate to reduce the stress experienced (Bushy, 2004; Gibb, 2003; Hugo, 2001; Melamed et al., 2006; Scopelliti et al., 2004). Relating this to the psychosocial perspective, job-related demands identified as being excessive can lead to burnout (Maslach, 1976; Cherniss, 1982).

The change in eustress to distress is very individualistic and may impact on the person's interpersonal skills, contributing to the reduction of self-esteem and outwardly affecting his/her relationships with work colleagues and family (Melamed et al., 2006). This deterioration can be insidious; individuals may not recognize when a fatigue factor originates, nor may they identify that there is a gradual deterioration within their own psychological wellness. It may take only a simple trigger to cause a downward spiralling of functioning and stress management, leading to the inability to cope with the simplest of tasks within the workplace. This poor interaction can lead to resentment from social networks and co-workers, without recognition from anyone that the individual is actually experiencing a decline in functioning (Melamed et al., 2006). It can be considered at this point that workplace burnout is being experienced. Subject to the severity of this deterioration, this may indicate the need for employees to move away from their chosen profession or take extensive leave in an attempt to come to terms with their inability to cope with the stress of the workplace (Heard \& Harris, 2004; Malach-Pines, 2000).

Cohen, McGowen, Fookskas and Rose (1984) contend that it is the notion that others will be available to provide support when needed that acts as a stress-buffering agent. The authors suggest different studies indicating that if there is a perceived support available for the health professional, it is negligible as to whether this support is received or not. The fact remains that it is this belief that support is available which impacts on the health and adjustment of the staff member and the eventual outcome for the individual.

\section{Stressful work environments}

There is vast literature that supports the notion that the health workplace can be a very stressful situation, particularly in the rural sector of the nursing field (Bushy, 2004; Gibb, 2003; Hugo, 2001; Melamed, Shirom, Toker, Berliner \& Shapira, 2006; Scopelliti et al., 2004). Rural and remote areas face unique issues and constraints relating to distances, population sizes and recruitment of appropriately experienced and skilled staff especially within community mental health teams. Many of these areas have seen significant withdrawal of resources with government economic rationalisation across all Australian States (Bushy, 2004; Carlin and Farnell 1985; Gibb, 2003; Hugo, 2001; Melamed et al., 2006; Pompili et al., 2006; Scopelliti et al., 2004).

The impact of stress can not only be derived from organizational, societal, personal and professional sectors but also environmental impacts must be considered in regard to 
maintaining employees' well-being. Workers at times may be in conflict with any or all of these factors in their work situation (Gillespie \& Melby, 2003). There is vast literature on rural health with much focus being placed on the detrimental effects rural and remote areas exert on individuals (Halcomb et al., 2005). These areas face unique issues and constraints relating to distance, isolation, poor technological support, population size and recruitment of appropriately experienced and skilled staff (Productivity Commission, 2005).

The workplace has a profound impact on employees' morale, physical and mental health, and personal identity. Many work demands create stress simply because they do not satisfy basic human needs. The intense nature of nurse-patient interactions and the stress associated with confronting difficult and challenging patient behaviours on a regular basis compound the physical and psychological demands on nurses in an already hostile work environment (Pompili et al., 2006). The working environment and the effectiveness of organizational structure were examined by Carlin and Farnell (1985) with organizational structures being identified as a major origin of workplace stressors, along with poor physical working environments. Lambert (1995) described unhealthy workplaces and work habits as causing stress, lowering productivity and creating physical and psychological difficulties for individuals. Workers suffering prolonged stress and ill-feeling towards their employing organization are more likely to suffer from poor self-esteem, burnout and violent outbursts (Lambert, 1995). Work environment evaluations and changes can minimize these problems and promote health and safety for employees. Workplaces and work habits that fail to allow for periodic unwinding create stress, erode physical and mental health and lower productivity. Lambert discusses the growing concern in Japan about work-related deaths. Karoshi, 'death from overwork', is a major occupational health problem and involves too many hours on the job, producing high blood pressure and high stress levels (Melamed et al. 2006). It is the second highest cause of death after cancer amongst workers in Japan.

\section{Unrelenting stress and burnout}

Melamed et al. (2006) present evidence to suggest that the literature regards burnout as continuous and prolonged exposure to stress, particularly related to the workplace. The authors acknowledge that there are facets in the coping process such as psychological withdrawal and that there is the concept of a recovery from this state of fatigue that passes after a resting period. Burnout, however, is conceptually distinct from Melamed's concept. The burnout phenomenon is multidimensional in construct, consisting of emotional exhaustion, physical fatigue and cognitive weariness. In a study undertaken by Melamed et al (2006), the results suggested there was a remarkable stability of the burnout syndrome regardless of the sample composition, attesting to chronicity. This study also revealed that a job environment in which there is chronic workload stress was more strongly related than personality factors and age. The authors report that this has led to an increase in workers' compensation claims across the United States of America, United Kingdom and the Netherlands, with Sweden having burnout as a diagnosis on medical certificates. Branco, Chambers, Fallon, Fraser and Howlett (1981) identify burnout as being a common experience in practitioners of the helping professions, regardless of the time spent working within their profession. The authors recognize the physical manifestations of burnout, with symptomatology occurring in the physical, cognitive, attitudinal, affective and social levels 
of functioning. Branco et al. (1981) recommend that professional training within the helping professions should include education about the signs and symptoms of burnout and its management.

\section{Preparing the nursing workforce}

In the last 20 years, there has been a marked change in the education of nurses, from the apprenticeship model to the academic model. It is argued that a section of this workforce from either model do not have the comprehensiveness in education when entering the workplace to meet adequately the needs associated with the various cultures and values of today's Australian society and the radically changing requirements of the Australian health system beyond 2000 (Clinton \& Hazelton, 2000; Happell \& Platania-Phung, 2005). This deficit is significant in the specialty field of mental health nursing. The impact of the change from psychiatric deinstitutionalization to community-based care has required implementation of a diverse community care framework, providing a range of community and hospital-based services. Sharrock and Happell (2002) purport there is increasing evidence to suggest nurses working in general hospital settings consider themselves as inadequately prepared, skilled or experienced to care for consumers with mental health issues. Campbell (1985) contended that the changes in work practices have led to decreases in job satisfaction. Stresses within the work environment, along with personal stresses, have contributed to feelings of the job becoming increasingly undesirable. Current literature suggests this argument is supported and continues to apply in current practice (Clinton \& Hazelton, 2000; Happell \& Platania-Phung, 2005).

For rural Australia, access to and provision of health-related services have been continuing factors in poorer health outcomes and have been greatly influenced by the economic downturn and changing rural demographics (Mahnken, 2001). Rural communities now require health services involving a more diverse range of health promotion, preventive, chronic and social care. Shifts in health policies during the 1990s reflected this changing need. Hegney et al. (1997) identified the geographical implications for health care in rural Australia. These authors contended that rural areas in general had fewer facilities with shortages of health professionals. They identified significant inter- and intra-State differences in the availability of ease of access to health care services. Major rural towns and regional centres were well provided with primary and specialist services whilst many smaller and rural communities failed to attract the most basic of health care services. Attention was drawn to the fact that accessing basic health care services for many rural Australians presented a major difficulty due to reduced services associated with decreasing population and demographics.

Humphreys and Rolley (1991) identified three themes that exist in any discussion of rural health care needs. The first of these was the specific difficulty associated with the provision of any health intervention, including staffing and hospital availability in remote and rural areas. The second of these themes identified the necessity for flexibility in the delivery of services, providing accessibility whilst considering the monetary cost involved to the health regions. The final theme these authors identified was related to the appropriateness of service models designed for metropolitan areas when utilized in rural regions. Many of these had proved to be unsuccessful in application. Referring to a study conducted in the Hunter Valley, NSW, the authors identified that rural residents expected complete 
competence from their health care provider, placing an additional stress on rural health personnel. Compounding this issue, and increasing the stress levels for the practitioner, was the considerable distance from acute care facilities, accompanied at times by 'fragile and erratic means of communication' (Humphreys and Rolley, 1991, p.69).

Health professionals working in the health sector make up $6.7 \%$ of the employed workforce in Australia (Duckett, 2005). Community Mental Health Teams (CMHT) providing illness treatment/rehabilitation based on the recovery model and preventative services of education, health promotion and prevention programmes are part of this cohort. The expectation placed upon this service is proving to be an increasingly difficult, if not near impossible, task to achieve and maintain in light of the socio-economic situation of rural communities (Bushy, 2004; Fraser et al., 2002). Effective delivery of health care in community nursing practice within rural areas encounters a range of barriers, such as the remoteness of some communities and the vast distances of travel required, and the isolation and fragmentation of supportive health service providers (Hays \& Beaton, 2004).

Since deinstitutionalization, mental health care in the community is now provided through collaboration between representatives from several disciplines (Cook \& Fontaine, 1991; Gibb, 2003; King, 2001; Murray \& Huelskoetter, 1991). The role of psychiatric nurses is significantly different to that of their equally qualified and skilled counterparts in other specialty areas of nursing. Cutcliffe and Goward (2000) contend that psychiatric nurses have a relationship with their clients that are qualitatively different to their counterparts in other disciplines. In psychiatric nursing, the role is based on the development of a mutually influenced relationship between the mental health consumer and the nurse. Pivotal to this relationship are the use of the self as a tool by the nurse and the closeness of the relationship that is formed (Maude \& Warelow, 2011; Young, 2011). A significant amount of trust in oneself is required by the psychiatric nurse, as this relationship can be problematic or unpredictable.

\section{Community mental health teams and unique issues}

Community mental health teams in rural and remote areas face issues and constraints specific to their locations relating to distance, population size and recruitment and retention of appropriately experienced and skilled staff (Bushy, 2004; Gibb, 2003). The rural remote community mental health nurse's work is influenced not only by the reduced resources but by the diverse and demanding role of first line managers of care for mental health consumers in the geographically challenging setting (Francis \& Chapman, 2008). Further contributing to their workloads, the community mental health teams extend their case management by maintaining mental health services to the general community. These teams are required to provide flexible and innovative programme development in preventing illnesses and planning of treatment approaches for a comprehensive network of services to meet the ever-changing needs of the general population (Croll, 1997; Gibb, 2003; King, 2001).

Lack of resources requires the community nurse to become extremely innovative and creative, with improvisation an important learned skill (Lauder, Reynolds, Reilly \& Angus, 2001). These issues are coupled with an increased demand for their services due to an agricultural crisis that, according to some researchers, Australia has been facing for some decades (Bryant, 1992; Fraser at al., 2002). This agricultural crisis has resulted from the 
decline in wealth in the agricultural sector (following several years of low rainfall and declining produce and stock prices), and the rationalization of government and private sector services that has led to a decline in the financial well-being of rural towns.

Strong et al. (1998) suggest that the major challenges facing health service provision in rural Australia can be identified according to four categories. These are:

- Health status: (generally lower in the rural sector), a rapidly ageing population (with a higher rate of illness chronicity), and higher incidence of lifestyle related diseases;

- Community expectations: self sufficiency in health, and skewed perceptions of government agendas to reduce costs and services;

- Infrastructure: logistical considerations in accessing specialist health services, poor transport between services with many consumers requiring escorting, disparity in the physical condition of the infrastructure of health facilities with many lacking appropriate security, and difficulty in the recruitment and retention of appropriately qualified staff;

- Service delivery: areas of low population fall below the level required to maintain a viable and quality service, service duplication in an adjoining community, and the unsuitability/rigidity of Commonwealth and State funding for the specific requirements of each community.

\section{The research study}

Although there have been attempts to investigate nursing science through the reductionist approach invented in a laboratory, it is not always possible to apply such approaches to nursing research or practice (Gerber, 1999; Whitehead, 2007; Tolley, 1995). Consequently, much nursing research has moved away from the traditional medical science model to the social science model of investigation grounded in the qualitative research paradigm (Ezzy, 2006; Owens et al., 1999; Walter, 2006; Wright, 1991). Qualitative methodologies involve exploring participants' perspectives and experiences and locating these within a wider social context. Data collection, which involves the interactions of the researcher and respondents, is recognized as being based on a subjective process (Simmons, 1995). Qualitative research permits data analysis within the research as it progresses in the identification of patterns of meanings and interpretations. The aim of this is to develop sociological theory that contributes to the understanding of the social world (Willis, 2006). New knowledge that is socially constructed must be understood in its political and cultural context (Taylor, 1993) expanding nursing knowledge with the developed new theories to be applied in practice.

From a theoretical viewpoint action research can be deemed to be both action learning theory and critical social theory (Carr \& Kemmis, 1990; Owens et al., 1999). Critical social theory allows for a collective inquiry into social reality with the potential for change in practice through collective analysis and action. This theory emerged after shortcomings were identified in both positivist and interpretive approaches to social science (Carr \& Kemmis, 1990; Owens et al., 1999). A direct correlation between knowledge and practice forms critical social theory, which results from the 'outcome of human activity' (Tolley, 1995, p.185). The separation of the ideal world from the real world may contribute to the theory-practice gap (Tolley, 1995; Owens et al., 1999). Action research is a methodology that 
facilitates a greater union between researchers and clinicians and thus is in a better position to address the theory-practice gap (Owens et al., 1999; Whitehead \& Elliott, 2007). It provides an ecological perspective in viewing social problems and individuals' behaviours, encompassing a focus on organizational, community, and cultural factors. In collaboration with participants, this form of research develops natural helping resources in communities rather than limiting the focus to professional resources only. This includes the change and development of new social policies and work environments. Action research can be described as a holistic social process facilitating change; organizational change is effected as this methodology marries the change process to the research findings (Owens et al, 1999; Whitehead \& Elliott, 2007). It provides a way to work with people in the research field in a non-hierarchical and non-exploitative manner, enabling participants to reclaim the authority to identify their own roles and to establish conditions within their work practices (Kemmis \& McTaggart, 1982).

Observation is a technique that facilitates description of actions, behaviours and interactions. It allows for individuals to be observed utilizing all their senses, including their verbal and non-verbal communication. Their perceptions, beliefs and assumptions can also be noted. The researcher examines within the practice context while not being dependent on categories of established theory and techniques, and constructs new theories defining means and ends interactively (Rolfe, 1996; Whitehead \& Elliott, 2007). Reason (1988) viewed expression as a mode that allowed the meaning of experience to be verbalized and to take form. This requires the use of a creative medium. Human inquiry facilitates this medium. Language is expressed in various forms and can be identified through words, actions, art forms and silence, and can be 'analogical and symbolic' (p.82).

As in all social research, action research involves people as key stakeholders/co-researchers who determine the appropriateness of both the action and the research. Wallis (1998) and Owens et al. (1999) identify that the collaboration and participation processes of action research are essential to facilitate the knowledge, skills and confidence needed to change practice and to maximize the link between research and practice. Participants in the research are known as the critical group and they work collaboratively with the researcher as coresearchers (Whitehead \& Elliott, 2007). Participation by all members of the critical group is the predominant factor giving rise to the emancipatory process, by allowing each member to become a co-researcher and to be given a voice (Whitehead \& Elliott, 2007). Collaborative reflection and action among those with shared concerns can implement social change through this method of research, which is conceptualized as a spiral of collective, selfreflective inquiry (Kemmis and McTaggart, 1988; Whitehead \& Elliott, 2007).

Susman and Evered (1978, p.587) describe the characteristics of action research as providing a 'corrective to the deficiencies' of positivist science. These characteristics are explained by these authors as being 'future orientated' by creating a more desirable future for people when dealing with their practical concerns. The authors describe an interdependent relationship involving collaboration between the researcher and the participant.

\section{The cyclic nature of action research}

The action research method includes a wide range of variations on a theme, including participatory research, collaborative inquiry, emancipatory research, action learning and 
contextual action research (Sheehan, 1996; Susman \& Evered, 1978; Whitehead \& Elliott, 2007). The cyclic or spiral process first introduced in the previous section involves the four steps of planning, acting, observing and reflecting (Kemmis \& McTaggart, 1982). The aim of the planning phase is to develop an exact description of what changes should be implemented into practice (Kemmis \& McTaggart, 1982). The critical group involved in the research carefully considers what is believed to be the most effective intervention to effect change of practice in order to resolve an identified problem (Kemmis \& McTaggart, 1982). Critical communication practice (the formation of abstract generalizations and concepts then testing and applying these in a new situation) facilitates a reflection-in-action and a reflection-on-action and provides the basis for subsequent cycles. It is designed to create change in practice and develop and refine theory within its local setting (Kemmis \& McTaggart, 1982; Owens et al., 1999).

The action step provides a rationale for strategic interventions aimed at an improvement in practice and greater understanding of the practice situation (Kemmis \& McTaggart, 1982; Owens et al., 1999; Whitehead \& Elliot, 2007). The second step, the planning step, is deliberate where controlled variations are implemented into practice and used as a platform for further actions in subsequent cycles. This step is guided by the critical group and takes place in real time. It may encounter variables and constraints such as the political climate and availability of resources (Kemmis \& McTaggart, 1982; Whitehead \& Elliot, 2007). It is described as fluid and dynamic, which requires instant decision-making by the critical group and the exercise of practical judgment (Kemmis \& McTaggart, 1982; Whitehead \& Elliot, 2007). The third step of action research, observation, serves to document and reflect on the effects of the action step, providing reflection for possible changes and thus being prospective to future cycles. With actions having constraints of reality, the observation step must be carefully reviewed, allowing for responsive and expanded views on the subject under consideration. Observing and reflecting on the action process allows identification of the implementation's constraints and benefits and any changes to circumstances, and provides a basis for subsequent reflection (Kemmis \& McTaggart, 1982; Owens et al., 1999; Whitehead \& Elliot, 2007). The final step, reflection, is retrospective, recalling action previously recorded in the observation step (Kemmis \& McTaggart, 1982; Owens et al., 1999; Whitehead \& Elliot, 2007). All of the identified material relevant to the action process is assimilated and related to the varying perspectives and circumstances observed. This step involves discussion amongst the critical group leading to evaluation of data and reconstruction of a subsequent action. Evaluation is an integral part of this step, assessing the effects of the action in terms of its impact on the thematic concern and the potential theoretical implications arising from the action research cycles (McCaugherty, 1991; Rolfe, 1996; Owens et al., 1999; Whitehead \& Elliot, 2007). The reflective step is descriptive, identifying progress for proceeding into any subsequent cycles, eventually establishing a final outcome to the research while allowing for reflection on what has happened and providing a basis for future planning (Kemmis \& McTaggart, 1982; McCaugherty, 1991; Rolfe, 1996; Owens et al., 1999; Whitehead \& Elliot, 2007).

By implying a system development, action research facilitates the maintenance and regulation of a cyclic process of diagnosing, action planning and taking, evaluating and learning generating theory. Theory grounded in action provides a guide for diagnosing problems and evaluating their consequences. The generation of theory is a deliberate process in action research. Theory generation provides for emancipation of practitioners 
from constraints and ideal practices, providing the means to create democratic conditions through collaborative practical discourse (Carr \& Kemmis, 1994; Whitehead \& Elliott, 2007). Implementation of the findings is built into the research process circumventing the possible situation of research findings not being put into practice, which may occur when using other research methodologies (Annells \& Whitehead, 2007; Carr \& Kemmis, 1994). Action research can provide both the flexibility and responsiveness required for effective change and a check on the adequacy of data and conclusions (Adami \& Kiger, 2005; Whitehead \& Elliot, 2007).

One of the main characteristics separating action research from other forms of research is that researchers have limited control over the environment in which it is conducted. Although traditional scientific approaches seek to produce an objective body of knowledge that can be generalized to a larger population, action research collaboratively constructs a descriptive and interpretive brief of events that facilitates a mutually accepted resolution to a problem identified by a group of people.

\section{Implementing an action research study}

Action research is a form of research that empowers participants to change their practice and gives ownership of this change to participants. It is designed to create change in practice, and to develop and refine theory within its local setting. Theory is developed from the bottom up and is generated by an interactive process within the cycles of the research (Kemmis \& McTaggart, 1988). Participatory action research facilitates implementation of research findings by empowering the individual with autonomy, decision-making processes, and programme design. Implementation of the findings is built into the research itself, thus circumventing the situation of research findings not being put into practice (Wadsworth, 1997; Whitehead, 2007).

An action research study undertaken was in a rural remote area health service in Australia which identified several deficits in policies that impacted on the wellbeing of staff and influenced the outcome for mental health consumers. Key outcomes from this research identified an inability to adequately meet quality care for consumers and carers, and ineffective frontline responses for people with mental health issues across a range of sectors in the rural setting. Through this research the participants identified an inadequately trained and sustainable supply of skilled mental health workers, lack of a valued and respected mental health workforce and inefficient organisational protocols contributed to the concerns in practice.

The objectives of this research was to work collaboratively with a rural Community Mental Health Team (CMHT) to examine the issue of workplace stress and, address issues specified by that group by empowering them to become active change agents through AR.

Two overarching themes drove the research cycles: staff safety, and, inadequate education of nursing staff to appropriately assess and manage a consumer with mental health issues. Through this a collaborative social process, action research, empowered participants to identify and change stressful factors identified within their practice indicative to rural remote community mental health teams. Critical social theory arose from identified problems within the context of the research setting permitting a new model of praxis to be established within the research study which should ensure a positive patient outcome and staff safety. 


\section{Research questions}

The questions that were addressed in this research were:

- 'What stressor(s) does a community mental health team in a rural and remote region identify as critical in the creation of occupational stress that may lead to workplace burnout, and

- How can the team overcome this particular issue/s in their setting?'

These types of questions are ideally suited to the Participatory Action Research methodology because it allows a group to be involved in the diagnosis of a problem and permits action to be taken that is conducive to establishing solutions that best suit the group's area of practice.

\section{Study aims and objectives}

Broadly, the objectives of the study were to work collaboratively with a community mental health team practising in the rural setting to examine the issue of workplace stress and address issues specified by the group. The specific aims of the study were:

a. To identify distinctive factors that impact on occupational stress associated with workplace burnout;

b. To identify what processes are currently utilized by the team to minimize occupational stress and the potential for workplace burnout;

c. To identify problems that lead to occupational stress and the potential for workplace burnout and strategies to overcome these problems;

d. To develop an Action Plan to address the problems identified;

e. To implement the Action Plan;

f. To evaluate the impact, if any, of the engagement of Action Research;

g. To evaluate and specify learnings from the implemented Action Plan and develop a theoretical basis for understanding the issue of workplace stress and burnout in community mental health teams in rural remote Australia.

\section{Ethical considerations}

Approval for this study was sought and obtained from the University of Adelaide Human Ethics Committee and the health service ethics committee where this research study was conducted. The research did not commence until ethics approval was gained from both ethics committees, with the research following all human research ethics guidelines. Each letter of approval was provided to the other ethics committee. Once completed, the CEO of the Area Health Service received an explanatory letter detailing the proposed research.

\section{Sampling}

Qualitative research uses human subjects to examine human experiences who then become known as participants. It is a non-statistical approach in understanding the depth and subtleties of the human experience (Jackson \& Borbasi, 2008; Llewellyn, Sullivan \& Minichiello, 2004; Whitehead \& Annells, 2007). Tending to be small in sample size, 
qualitative research uses various sampling techniques that result in the selected sample being 'information rich or experienced in the phenomenon of interest' (Jackson \& Borbasi, 2008, p. 167). This study adopted the purposive sampling technique.

\section{Sample population}

The population of interest in this study refers to the health care workers working within this health area (Llewellyn, Sullivan \& Minichiello, 2004). The selection of participants in the sample population reflected the key characteristics of a representative sample (Whitehead \& Annells, 2007). These included Community Mental Health Team (CMHT) members, Registered Nurses registered with the State nurses' registration body, Clinical Nurse Specialists, Clinical Nurse Consultants, Health Promotion Officers, social workers, occupational therapists and psychologists.

\section{Purposive sampling}

Based on the limited number of staff within this specific isolated CMHT this sampling technique was deemed to be the most suitable for this study. This form of sampling (deemed to be judgmental sampling) enabled the researcher to select participants best suited to address the issue under study and to target a representative selection of participants (Jackson \& Borbasi, 2008; Mugo, 2003; Patton, 1990; Walter, 2006; Whitehead \& Annells, 2007). Experts in this specialty field of mental health service provision were selected on this basis. Despite the sample size being limited, Jones (2002) argues that the focus of qualitative research is on the depth and richness of text rather than on participant numbers.

\section{Inclusion criteria}

Suitability for participant inclusion in this study required characteristics that represent health staff that have sufficient experience in the phenomena under examination. It was determined that staff with a minimal work history in a rural remote region would not have had sufficient exposure to this and therefore health staff who have practised nursing and health care in a rural remote area for a period of not less than twelve (12) months would be accepted into the study. These also ensured participants were selected to give a cross-section of years of experience.

\section{Limitations of sampling method}

The limitations of this method of sampling must be identified. Through the sampling method the researcher attempted to achieve a representative cross-section of the target population in order to increase the efficiency of the research study (Jackson \& Borbasi, 2008; Whitehead \& Annells, 2007), despite the fact that the Area Health Service was quite small. The risk of conscious sampling bias may exist and this method did not allow for the precision of the researcher's judgment to be measurable. It did not provide any external objective method for assessing the representativeness of the selected group. Despite these limitations, the majority of nursing researchers and qualitative researchers use nonprobability sampling (Polit \& Hungler, 1991; Whitehead \& Annells, 2007). 


\section{Critique of the research study}

A researcher strives to do justice to the research being undertaken without subjective dogmatic theoretical viewpoints. Openness in a research methodology permits the researcher to appreciate biases and perspectives that may influence the interpretation of data (Gerber \& Moyle, 2004; Silverman, 2006; Willis, 2006). Qualitative research methodologies provide the opportunity to undertake research within the social context and allow the researcher to become closer to the study (Whitehead \& Elliot, 2007). The reciprocal relationship between the researcher and the participant facilitates recognition of backgrounds that may influence how the research is conducted (Gerber \& Moyle, 2004). In doing this, there are certain strengths and limitations whatever methodology is adopted. For this study, both the strengths and limitations of action research are listed as key points.

\section{Strengths}

The strengths of this study must be acknowledged as contributing to the success of the research. These are identified as:

i. It was focused on a specific problem in a defined context, not on obtaining generalized information

ii. the application of fact finding to practical problem solving

iii. generation and validation of theories through practice

iv. individual input guided the course of the research

v. participants were empowered to shift the parameters in which they practised

vi. participants had ownership of the project

vii. individuals took responsibility for change within the organization and,

viii. enhancement of practice skills flowed through to patient care (Greenwood, 1994; Hart \& Bond, 1995; Holter \& Schwartz-Barcott, 1993; Whitehead \& Elliot, 2007).

\section{Limitations}

Equally as important to be recognized in this study are the limitations that may have impacted and/or influenced the outcome of the research. These are listed as:

i. Research conducted within the scientific realm must conform to the canons of the scientific method to be granted legitimacy. It is questionable whether this qualitative research method could generate evidence that is recognized as truly scientific

ii. qualitative forms of research reflect the humanistic perspective thus this study required a different type of study design

iii. underlying democratic and civil discourses guided the process of investigation that then provided a greater chance of researcher bias

iv. action research may have facilitated a forum that allowed the researcher and participants to have an agenda that gave priority to meeting their own goals. It did however facilitate social change

v. the method of sampling did not allow for the evaluation of the precision of the researcher's judgment

vi. difficulties and dilemmas arose over the availability of persons within the group to attend critical group meetings. This was due to demands such as shift work and patient emergencies and the remoteness of the setting, and 
vii. co-workers' acceptance of the research process in the local environment may have had an impact on the expected workload of those not involved in the research (Greenwood, 1994; Hart \& Bond, 1995; Holter \& Schwartz-Barcott, 1993; Whitehead \& Elliot, 2007).

\section{The study plan}

Following the Susman and Evered (1978) model with the Pearson (1989) adaptation, the critical group in this study was selected in the contracting stage. Similar to other action research approaches previously identified, this model involves a cyclic process.

The Development Phase provides for the client-system infrastructure to be established. This client-system infrastructure is the social system under study in which the participant members exist. In this phase, understanding and general consensus is developed between all parties. Each participant is given a speaker position, thus addressing the issue of participant bias agenda. Common power comes from a shared understanding permitting democratic contribution to the critical group and providing respect to each contributor without judgment.

The Diagnosing Phase involves problem identification and determines what is happening within the setting. It involves the collaborative analysis of the social situation by the researcher and the participants of the research. Theories are formulated concerning the nature of the research domain. A collective postulation of several possible solutions is examined from which a single plan of action emerges and is implemented. In this phase, a problem is identified and data is collected for a more detailed diagnosis.

The Action Planning Phase gives an exact description of what changes will be implemented into practice. Through a collaborative process, the researcher and the co-participants collate the information discussed in the previous phase and determine an appropriate action towards resolving the identified problem.

The Action Taking Phase implements mutually agreed changes in practice. A defined course of action is undertaken, directed at an area of practice perceived in previous phases to warrant amending. Deliberate and controlled variations are implemented into practice and used as a platform for further action in subsequent cycles.

The Evaluation Phase reports the findings and data generated by the action taken. Data analysis is undertaken based on the results of the interventions and the findings are interpreted to determine how successful the action has been. This phase serves as documentation of the effects of action, providing reflection, and thus being prospective to future cycles.

The Learning Phase provides critical reflection, theorizing and analysis of identified themes. Retrospectively it recalls previously recorded actions, reviewing the effectiveness of any actions taken guided by the evaluation phase. The emergence of new knowledge is identified taking the research to a new level. Gaps in knowledge can be identified and theories can be deduced with the potential aim of informing new policies.

\section{Becoming change agents}

The concept of a change agent can be related to those within an organization who provide 'technical, specialised or consulting assistance in the management of a change effort' 
(Pearson, 1992, p.25). The deliberate process to change the status quo and reduce the stressors experienced in the Area Health Service within the research study required a deliberative and collaborative partnership between this client system and the researcher (Holter \& Schwartz-Barcott, 1993; Whitehead \& Elliott, 2007). The participants, who were eager to bring about change, turned actions within their practice into research strategies (Bond, Barker, Pearson \& Proctor, 1996) by adopting the role of co-researchers. This process of becoming change agents can be said to be a characteristic of action research (Baskerville, 1999; Holter \& Schwartz-Barcott, 1993; Street, 2004). The team considered for this research was comprised of the CNC, three Registered Nurses (RNs), a RN (Child and Maternal Health) who held a Postgraduate Diploma of Mental Health Nursing, and a RN undertaking a Postgraduate Diploma of Child and Adolescent Mental Health.

This team is employed as the Mental Health Support Team and it receives services from the Community Mental Health Team located in the regional centre of the Area Health Service. This regional centre is located approximately 150 kilometres from the site and provides limited visits once a fortnight to the site if the regional team deems there is a client need. All mental health consumer consultations are carried out by the MHST at the site, with a variety of interventions undertaken by this team to address any specific needs. Consultations and assessments are undertaken by the $\mathrm{CNC}$, who is frequently called at any time and regardless of whether or not she is on duty. She is also responsible for assisting GPs who have patients with mental health issues/referrals; providing outreach for Aged Psychiatric services, Adult Mental Health services and Child and Adolescent Mental Health services; supporting clients and carers; assessment and early intervention in mental health; mental health promotion and generalist counselling.

While not all participants within this study had continuous practice in the region under study, each individual had experienced the stressors found in rural regions. Several similarities and themes became obvious during these discussions. These ranged through:

- isolation from regional support services during critical incidents;

- $\quad$ very poor access to a contact person for debriefing after a critical incident;

- absence of technological support (no mobile phone service or pager system was operational in the region);

- $\quad$ long distances involving extensive travel when accessing clients;

- the remote location of farm properties, each with several closed gates that visitors had to pass through to gain access (the golden rule of farmers-each closed gate must be closed again after passing through it);

- seasonal climatic conditions producing ice and snow on roads, hampering access to clients;

- $\quad$ political dilemmas when involved in interdisciplinary discussions;

- difficulties with anomalies associated with different Mental Health Acts and hospitalisation procedures between the two States;

- the delay in accessing specialist care/interventions (lengthy periods of up to eleven hours);

- difficulties with transporting clients after hours due to the challenges of driving large distances (for example, a two-hour delay on the road after hitting a kangaroo);

- poor access to emergency transport resulting in excessive delays for client assessment/hospitalization (the ambulance may not be available for a number of reasons); 
- $\quad$ limited professional supervision;

- limits to assistance from the police when they were required elsewhere.

\section{Diagnosing phases}

These phases of the research provided the opportunity for the critical group to speak openly about issues that caused the greatest amount of stress for each of them. The enormity of the issues that concerned them was notable. On several occasions, these clinicians had limited support and recognized that the geographical isolation factor contributed to feelings of uncertainty and doubt in the provision of effective and safe practice. Lengthy discourse occurred within the critical group and it was decided preference should be given to a few significant issues then narrowed down to reflect the most imperative stressors to be addressed, rather than attempting to address all stressors. It became evident there was consensus that the danger of being alone or with limited support presented the most concern for all participants, particularly with the unpredictability of consumers with mental health issues. There was a level of despair amongst the members of the group as to how big this issue was, with no idea as to how it could be resolved. After careful consideration, staff safety became a predominant theme that the group decided should be considered in the first instance. There was a degree of relief when this was proposed despite the fact that no decision had been made as to how it would be addressed.

There was significant discussion amongst the group that their levels of distress were not necessarily debilitating as a direct result of the contact with consumers in crisis, but they agreed that such incidents did cause them concern due to their uncertainty of practice and knowledge in these matters. There is a widely held belief that the nursing profession is inherently one of the most stressful occupations within the workplace (Rees \& Cooper, 1992). Some of these stressors include dealing with death and dying, severe and emergency illnesses, aggressive and abusive patients and relatives, long working hours, shift and weekend work (Descamp \& Thomas, 1993; Kennedy \& Grey, 1997; Schaefer \& Moos, 1996).

The nature of mental health nursing, in which emotional clients seek help by imparting information to nurses (Gladding, 1992; Maslach, 1982), can lead to the phenomenon of workplace burnout (Freudenberger, 1989; Maslach, 1986). Patients expressing very strong, direct and negative emotions to the health professional during the course of therapy can at times direct this towards the health professional (transference). Maslach and Jackson (1981) identified that mental health professionals scored lowest on personal accomplishment and highest on emotional exhaustion on the Maslach Burnout Inventory when compared with other professionals. For the critical group the combination of insufficient education in mental health nursing and the nursing skills required to deal with the demands of such intensity proved to be of significant concern. Greater expansion of their concerns led the group to the impact of the unrelenting stressors particularly experienced by the MHST leader.

The critical group identified that patients frequently accessed the ED with mental health issues as first point of contact under the guise of general health concerns. The ED staff lacked the skills and knowledge to assess and treat these consumers appropriately prior to any access to the CMHT. The ramifications of this are twofold. First, the consumer may have the appropriate treatment withheld, as statistics show waiting times for treatment in EDs 
have been problematic for many years. Secondly, the professional and personal safety of nursing staff may be compromised. In Australia a major responsibility of the employer is to ensure the well-being of the employee (NSW Occupational Health and Safety Act, 2004; Victoria Occupational Health and Safety Act, 2004). These laws provide for a general duty of care by employers to provide a safe and healthy workplace and one that is free from psychological and physical hazards. Occupational health and safety legislation throughout Australia has now been implemented in an attempt to reduce workplace injuries and reduce workers' compensation claims.

The helplessness of the situation in the ED as perceived by one group member was clearly articulated. This group member felt that despite several strategies having been implemented to provide nursing care to these clients in an effective and positive manner, there was little support within the health sector, including the emergency services. Because of the emphasis in mental health legislation across Australian States of nursing people in the least restrictive environment, a wide range of crisis intervention models is being developed that incorporate a multidisciplinary approach to the management of people with a mental illness. These were discussed at length by the critical group.

These models provide interventions as a solution to treating the exacerbation of psychiatric symptoms that may have resulted from poor medication compliance, physical illness and exposure to environmental stressors. In a relapse into a psychotic episode, sufferers may experience symptoms resulting in disturbed and difficult behaviour. This may be exhibited in aggressive and threatening outbursts either vented towards themselves or others. Crisis intervention at this stage becomes imperative to prevent further deterioration of an uncontrolled situation. The flow-on effects of continuing this type of management of mental illness, however, become time-consuming and stressful to implement for community mental health teams, with staff burnout becoming an increasing concern (Joy, Adams \& Rice, 1999).

Staff safety became a central focus during these discussions within the critical group. Complacency due to the location of the town led some critical group members to admit that they had not, at times, considered safety factors when dealing with unknown clients. Others acknowledged that, due to a transient population, they had been concerned about unknown persons accessing the health service regardless of the nature of their illnesses.

Benveniste, Hibbert and Runciman (2005) discuss the issue of critical incidents in Australia involving mental health patients. In reports from twelve EDs, 16 per cent of all reported incidents (190 of 1214 incidents) involved violence (p.348). Mental health problems were patient-related contributing factors for over half of the violent incidents, with alcohol or drug intoxication contributing to more than 25 per cent of violent outbursts. The Australian Patient Safety Foundation has developed systems to collect, aggregate, monitor and analyse incidents related to patient safety since its formation in 1988. The Foundation created a taxonomy and software which became the Australian Incident Monitoring System to reanalyse data from the Quality in Australian Health Care Study in 1998. A classification of health care incidents including adverse events and near misses was developed.

The incidence of psychological and psychiatric work-related injuries tends to indicate that employers may not have taken reasonable care of employees. The progressive disillusionment and loss of idealism within the workplace is deemed to result in detachment and decreased workplace effectiveness with increased absenteeism. Stress injuries are as 
liable as any other injury to lead to prosecution of employers under the law (NSW Occupational Health and Safety Act, 2000, Sec.3c; Victoria Occupational Health and Safety Act, 2004, Sec. 21).

\section{The action planning stages}

These stages involved consideration of alternative courses of actions to achieve improvement or resolve the problems identified by the critical group. Mental health treatment involves nursing staff interacting in many aspects of clients' lives. It is imperative that all interactions are well planned and have continuity across all staff members to ensure both clients and staff remain safe. Once the group had agreed that there was a clear need for interventions to overcome their safety need and the level of staffing in crisis periods, several action plans were discussed. This section outlines the development of these action plans, which would be later refined and implemented and adopted by the health service in providing an appropriate service. Discussion around these action plans centred on regaining control over the health care environment and maintaining staff safety.

In the work situation a stressor can be deemed to be either resolvable (short duration) or prolonged according to how it is viewed and the context in which nurses may find themselves (Pines \& Aronson, 1981; Pines \& Maslach, 1978). Individuals have different responses to stressors, ranging from slight psychological arousal with minimal performance deterioration to an intense arousal with psychological distress (Lazarus \& Folkman, 1984; Light, 1981; Turnipseed, 1994). When examining this situation, an initial distinction can be made between the problems that are experienced as challenges requiring innovative problem-solving ideas to bring about a resolution and ongoing problems causing distress. This could be due to personal needs not being met, with expectations or demands being beyond the control or exceeding the limitations of the nurses involved which requires extra energy resources when confronting the situation. Associated with stress from this level and linked to the burnout syndrome is reduced organizational efficiency and work-related problems such as staff turnover, low morale, poor quality of patient care, absenteeism and, interpersonal problems (Jackson and Maslach, 1982; Maslach, 1979; 1981; Turnipseed, 1988).

\section{The action taking stages}

These phases saw the courses of action considered in the previous stages implemented into practice. The critical group continued to examine a range of emergency triage tools from various Australian States and develop ideas that could be useful to include in a tool specific to their organization. Limitations were identified in many tools but modifications were suggested that could be adopted. The mental health initiative undertaken by the Victorian Government involved 41 teams on a national basis and was the first major initiative of the Emergency Care Community of Practice (Department of Human Services, Victoria, 2007). Teams of mental health and ED clinicians collaborated to improve the care of mental health presentations to EDs. The focus of the project was on the ED triage and assessment of patients with mental health issues, and sedation of acute emergencies involving agitation or behavioural difficulties. A literature search undertaken by Broadbent, Jarman and Berk (2004) identified scant literature addressing the provision of triage and management guidelines to assist nurses in making objective clinical decisions to ensure appropriate care for clients with mental illness. The authors examined the need for such guidelines and 
reviewed several mental health triage scales that had been evaluated for use in EDs. The results indicated that the effective implementation of triage scales had seen improvements in staff confidence and attitudes when dealing with clients with mental health problems. This resulted in improved outcomes for clients.

The suggestion from various group members was that the identified existing triage tools be disseminated among hospital and community staff to gain feedback on what could be included into the tools to become locally relevant. The critical group recognized the value of the input from this staff which would give a cross representation of what the various needs would be from varying perspectives.

The ensuing discussion led the group to identify existing emergency triage tools that could be used as guidelines in developing a triage tool specific to the area under study. It was acknowledged that the existing tools were based on well-resourced medium-sized hospitals and did not adequately address the issues inherent in this region. The group recognized that it was not a matter of adopting a suitable tool but of creating tools that complemented each other and became user friendly. The Action Plan developed from this would involve input from all staff within the hospital for inclusion into the creation of these tools to ensure it would also be a suitable and workable solution for the MHST whilst remaining a workable document for hospital staff.

Ongoing discussions led the group to choose several aspects from a range of existing emergency triage tools from various Australian States. Although they did not cover the exact needs of the Area Health Service involved in the study, they provided a guide as to how the critical group could develop the tools needed for the specific needs of this organization. An investigation into triage tools by Hegney et al. (2003) found that there has been considerable variation in the application of the Australasian Triage Scale (ATS) since its introduction. The authors identified a need for improved uniformity in the application of the ATS by triage nurses. A reproducible, reliable and valid method to classify the illness acuity of ED patients is required regardless of which hospital is being accessed. Their impressions were that a standardized tool would be of considerable value to emergency nurses. It would support nurses working in this challenging area by promoting standardization and decreasing subjectivity in the triage process. A study undertaken by Shaban (2006) revealed that problems of routine mental status examinations (MSEs) and mental health assessments (MHAs) by psychiatrists, physicians and nurses were well documented, however were too lengthy and complicated. This indicated such assessments were unsuitable for use in emergency situations. Shaban (2006) referred to an American study (Kaufman and Zun, 1995) which examined the use of a quantifiable Brief Mental Status Examination (BMSE) for emergency patients. The study comprised a six-item BMSE and was administered to 100 ED patients who warranted an assessment of their mental status. The results of this study indicated examiners rated the BMSE as useful in $98 \%$ of cases. The study concluded that the BMSE may prove to be a valid and useful tool for assessing the mental status of emergency patients in both pre-hospital and ED settings. This supported the critical group's decision to design a framework that was user friendly and simple to implement.

\section{The evaluation phases}

Following the completion of the action taking phases a collaborative approach was used to evaluate the outcomes. These phases determined whether the theoretical effects of the action 
were realized and whether these effects provided a suitable outcome. The final two cycles of the four cycles undertaken in the action research model used in this research reflected the final development of the 'Emergency Flowchart, Triage Tools and the Risk Monitoring Chart' based on the two overarching themes of staff safety and limited knowledge of mental health nursing. Personal safety was indicated as being crucial for staff given the unpredictability of mental health consumers and the limited resources for assistance in violent situations. Literature reported violence in the workplace is often unreported with attempts by nursing staff to de-escalate a situation to preserve the safety of other staff and patients. Various occupational health and safety controls were considered in attempting to reduce the potential of violence and injuries. However, it was recognized that rural and remote areas presented unique situations where many of these controls could not be facilitated.

\section{Specify learning phases}

These phases were undertaken as the last formal phase of the action cycle. The knowledge gained from the previous action research phases was used to resolve the staff safety issue by restructuring organizational norms to reflect the new knowledge gained in the research. This additional knowledge provided the foundations for the critical group to maintain focus on the identified stressor leading to the diagnosing phase of the next action research cycle. The theoretical framework provided relevant knowledge for future research settings (Baskerville, 1999). In this study, the specific learning revealed that stress from the workplace impacted on the functioning levels of nursing staff. Despite a nurse's feeling of how he or she is able to cope, if there is a perceived loss of control in one's practice the stress levels increase. In general, it appeared that a simpler approach to reducing the stress within the ED and for the MHST leader should be adopted in keeping with organizational economic constraints. Having determined that the original action plan was not a suitable option for the organization, the critical group examined alternative strategies to change practice. Some of these alternatives were identified in feedback from hospital staff. The specific learning indicated that the group believed through the action research process they had implemented a strategy that would significantly reduce their workplace stress. It reflected the collaborative and cohesive process required to initiate new programmes into the workforce. Staff and client safety should be a priority and staff should feel comfortable and supported in decision-making to determine clinical assessment and treatment without prejudice. The critical group had achieved this with the introduction of the emergency flowchart and triage tools.

\section{A nursing model of practice}

From the initial theoretical concept the reduction of stress and an increase in occupational health safety and wellness was well discussed. The critical group was able to assert their need to address such significant issues and design a change in praxis to reflect this. Several factors contributed to this requirement for a variation to practice norms. This became central to a new nursing model. The theory generated from the research cycles saw the critical group being enabled to identify circles that intersected allowing a complete interaction of all concepts whilst maintaining the core circle of reduced stress. These are identified as: 
- An increased occupational health, safety and wellness, and, improved positive patient outcomes.

- Issues relevant to rural and remote nursing practice

- A change to a positive cultural influence within the workplace would provide the nurses with a relationship of mutual respect.

- Education and up-skilling in nursing knowledge and best practice.

- Support and acceptance of change between management and themselves.

- The amelioration of knowledge deficit through ongoing education to all nursing staff would provide the knowledge and skills required to effect a therapeutic practice when dealing with consumers with mental health issues.

- $\quad$ Safe practice environment and support in decision making.

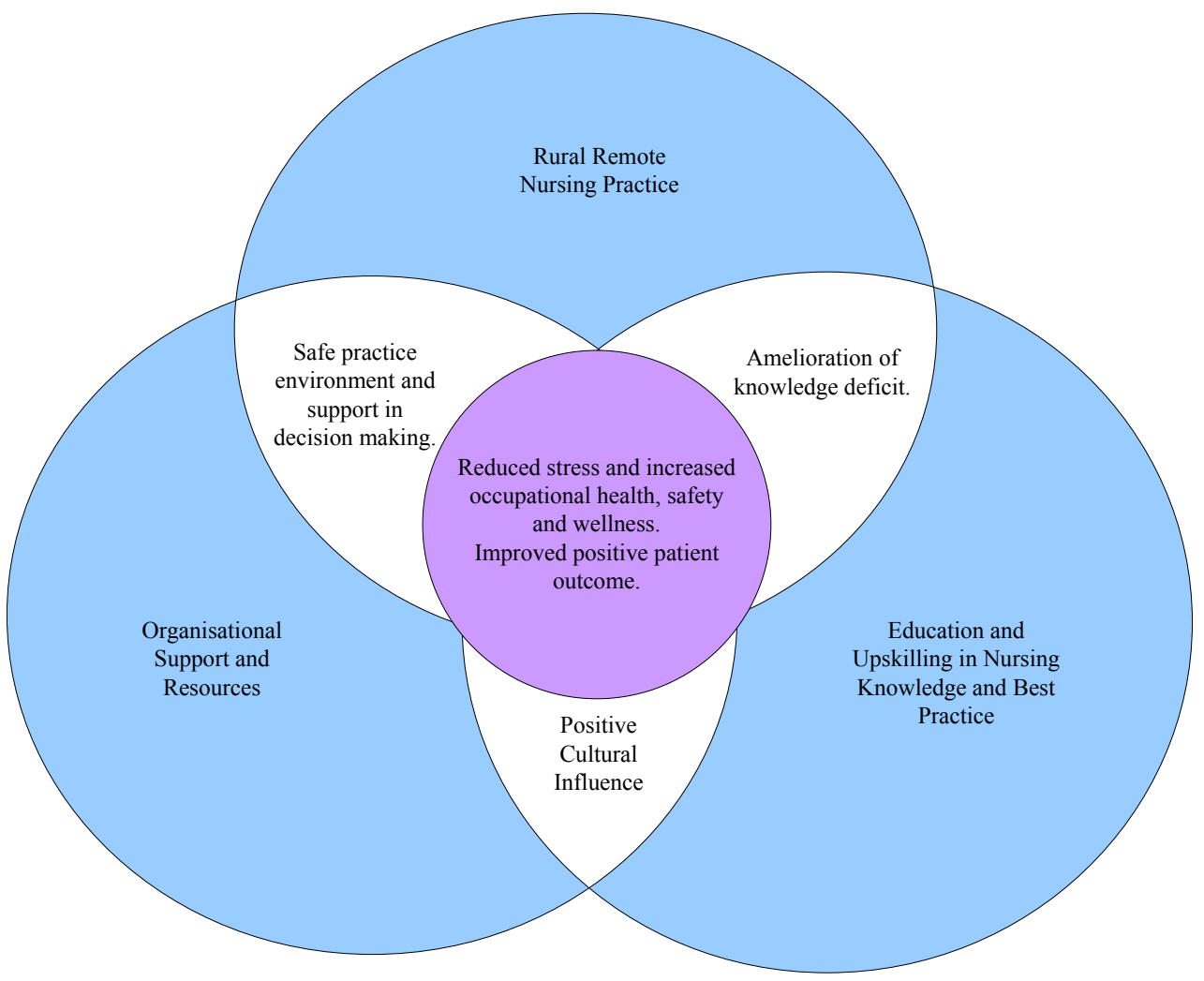

Fig. 1. Conceptual Model of Praxis.

\section{Educating the nursing workforce}

Many community mental health workers in Australia were practitioners in the psychiatric realm prior to the various Mental Health Acts (e.g. Victoria 1986 and New South Wales [NSW] 1990) and were required to undertake service provision for consumers of mental health services at a time when limited rehabilitative education had been afforded to the 
clinician. Prior to deinstitutionalization in Australia in the early 1990s it was recognized that custodial care was no longer an acceptable practice; however, there was only a decade or so (1985-1994) where rehabilitative care education was afforded to psychiatric nurses. This has meant that many of nursing staff who had been educated in psychiatric nursing practice under custodial care practices left the stand-alone institutions ill-prepared to work in the community or general hospital psychiatric wards (Clinton \& Hazelton, 2000; Croll, 1997; Glasson, 1996; Kenny \& Duckett, 2003). Their primary role had been to address and care for patients who had a diagnosis of mental illness with the necessary support and safety from within an institution. The new concept from a community mental health focus saw the nurse having to deal with the needs and requirements of clients from a primary care perspective within community settings. This may have occurred without the consumer necessarily having a formal diagnosis of a mental illness.

Concurrent with the shifting of education from hospital training (an apprenticeship model) to university training in a comprehensive nursing degree (an academic model) there was a significant depletion of the workforce within the psychiatric nursing industry. In one Australian State, the nursing workforce recruitment in rural regions is predominantly from nursing students graduating from regional universities (Kenny \& Duckett, 2003). Preference for nursing students wanting to pursue career paths in the more glamorous areas of nursing creates a deficit in the potential recruitment pool. This has led to a history of poor recruitment and retention in the psychiatric nursing workforce, particularly evident in rural and remote contexts (Gibb, 2003).

Clark, Brown, Hughes and Motluk (2006) discuss education in improving triage of mental health patients in general hospital EDs. The authors contend there is a distinct lack of knowledge, expertise and confidence in undertaking psychiatric assessments by generalist nurses which leads to less accurate assessments for these patients. This is supported by Kerrison and Chapman (2007) who discuss what general emergency nurses want to know about mental health patients presenting to ED. In their investigation, set in a Western Australian hospital ED, the authors refer to non-mental health trained nurses as ill-equipped in psychiatric knowledge, assessment and communication skills.

\section{Reflection on action research methodology}

This study employed the Susman and Evered (1978) model of action research and the use of critical social theory based on Habermas' (1971) assumption that people have a basic need to act independently and are capable of self-reflection. This study permitted the participants to effect change to their practice through embracing the research study with the belief they could contribute to the well-being of the organization and the body of nursing knowledge. The Susman and Evered (1978) model of action research proposes sequential phases of diagnosing, action planning, action taking, evaluation and specify learning. Within the diagnosing and action planning phases an opportunity existed for the participants to respond to an existing stressor, giving rise to rich data. An informal process was adopted to implement an action taking phase that had been designed to incorporate ideas from the expanded stakeholders and the critical group. Extensive evaluation of this action taking phase led the group to carry out a review of best practice in other Australian States. The purpose of this review was based on recommendations from the stakeholders and provided 
an opportunity for the group to meet the needs of the 'nurses at the coal face' in reducing a major stressor.

The prominent involvement of the critical group to examine the thematic concern and develop the tools to guide staff in clinical pathways in ED is characteristic of action research. The premise that the purpose of action research is to solve practical problems through direct contact with practical problem situations (Lauri, 1982) was validated in this study. Throughout the research the critical group contributed by sharing, suggesting, advising, debating, accepting each others' ideas and recognizing and valuing experiences. Through this process the group effected changes within their practice by developing tools to assist nursing practice and reduce significant stress within the workplace. Responsibility was a shared role, with the group taking control of how the research progressed. This emancipatory process is characteristic of action research, allowing the group to address their own concerns relevant to the thematic concern. Participant validation provided a process for checking accuracy and completeness of researcher interpretation. This reflection allowed each participant to ensure their voice was accurately reported without researcher bias tainting their perspectives (Titchen \& Binnie, 1993). Limitations existed for this method of validity as not all participants were at every meeting to obtain consensus.

\section{The concept of change}

The critical group worked well within this study to effect changes to their practice to eliminate the two significant stressors identified. Their development of clinical pathways for managing clients in the ED and the acknowledgement of the need for education indicated the staff's commitment to shape and mould their nursing practice in an effort to strive for best practice and maintain their own wellness. Change and its effectiveness are difficult to measure and are not always apparent for some time (Meyer, 1995). The change proposed in this study aimed to solve problems associated with occupational stress. An understanding of the basic nature of change influences the effectiveness of change techniques (Lancaster, 1982) with success depending largely on organizational and individual qualities of participants (Lancaster and Lancaster, 1982). The qualities of a change agent include accessibility, trustworthiness, honesty, being goal focused while assisting others to do so, and facilitating openness in discussion and listening (Lancaster, 1982). Trust is the key element among participants involved in change (Lancaster, 1982) with change being effectively achieved by academically prepared, practising nurses introducing a systematic and reasoning approach to change (Pearson, 1992). The critical group members became change generators (leading conversion of issues into felt needs) and change implementers (agents implementing the change after the felt need was identified) (Pearson, 1992).

\section{Conclusion}

Change and its effectiveness are difficult to measure and are not always apparent for some time. The change proposed in this study aimed to solve problems associated with occupational stress. An understanding of the basic nature of change influences the effectiveness of change techniques with success depending largely on organizational and individual qualities of participants. The qualities of a change agent include accessibility, trustworthiness, honesty, being goal focused while assisting others to do so, and facilitating openness in discussion and listening. Trust is the key element among participants involved 
in change with change being effectively achieved by academically prepared, practising nurses introducing a systematic and reasoning approach to change. The critical group members became change generators (leading conversion of issues into felt needs) and change implementers (agents implementing the change after the felt need was identified).

Nursing literature has previously examined occupational stressors and burnout as separate identities but has not considered these factors jointly in relation to the impact of a hostile work environment within rural, remote and isolated community mental health teams. The contribution of this study to the nursing profession is demonstrated through its potential to enhance community nursing practice to deliver effective holistic nursing care to consumers with mental health issues whilst maintaining their own psychological and physical wellness.

The impact of stress can be both advantageous and detrimental to an individual depending on his or her vulnerability at any given time. The degree of intensity of stress impacts on homeostasis for the individual and the degree of effectiveness of that individual's coping mechanisms. This results in the level of wellness for the person and the ability to cope with workplace demands.

Occupational stress and workplace burnout are significant issues affecting modern day workplaces. Occupational stress has been linked to a decrease in physiological well-being of individuals. This results from a combination of low job control, high job demands and low work-related support. It is apparent that the helping professions have endured a significant shift in praxis with the changing profile of the health system, cost-control measures, working conditions and societal expectations, and that these changes have likely added to stresses experienced by health practitioners, particularly in the rural remote setting.

The preparation of the workforce in today's society, particularly in nursing, may have impacted on the individual in coping with workloads. The change in nurse education from exposure to the rigorous demands on nurses under the apprenticeship model to the academic model has seen the nursing students less workplace ready. This is particularly evident in the psychiatric nursing field.

The action research process, being a holistic process, facilitated this change in practice, developed and refined theory as it proceeded in a cyclic fashion within this local setting. It concerned actual not abstract practices in the social world in which these participants practice. This methodology facilitated examining the significant stressors identified by the CMHT that caused distress, allowing them to implement changes in their practice.

A combination of factors, the appraisal and interpretation of the situation, responses to stressors and coping mechanisms and appraisals of outcomes determine whether a potential stressor is perceived as a threat to the individual. Based on this assumption it was proposed that individuals working in a collaborative process could influence changes in their practice using an action research methodology to reduce the physical and psychological impact to the employee from a significant stressor.

This study set out to examine which stressors a CMHT in a rural and remote region identify as critical in the creation of occupational stress and, potentially, workplace burnout and how they can overcome these particular issues in their setting. Unrelenting exposure to workplace stress is suggested by literature as being significant in the burnout phenomenon that has seen an increase in workers' compensation claims around the world. Burnout, 
common among the helping professions, impacts across the biopsychosocial perspectives of peoples' lives.

The aim of the study was to work collaboratively with a community mental health team to identify the distinctive factors that increase and reduce occupational stress associated with workplace burnout. An examination of the processes that were currently utilized by the team to minimize occupational stress and workplace burnout was undertaken; and which of the problems that led to occupational stress and workplace burnout were to be explored. In exploring what strategies could be developed to overcome these problems, an Action Plan to address the problems identified would be introduced. The implementation of the Action Plan would: evaluate the impact, if any, of the engagement of action research and evaluate and specify the learning from the implemented Action Plan. The underlying assumption in this study was that occupational stress could have deleterious consequences for employees and may lead to workplace burnout. This stress could be from any internal (within an organization) or external (from outside the organization) source.

The forum provided an avenue that could reduce stressors significantly and prevent ongoing occupational stress that contributes to workplace burnout. It offered an opportunity to work with a group of participants in a non-hierarchical and non-exploitative manner and enabled members of this group to identify their roles as effective practitioners, empowering them to effect the changes they deemed as essential criteria to reduce the stress they were experiencing indicative to their remoteness.

Critical reviewing throughout the data collection attempted to understand and redefine these significant issues. It aimed to acknowledge the way things were relative to how things could be improved from organizational, personal and wider community perspectives. Simple principles and guidelines of action research were followed potentiating acceptance as a rigorous research approach from a positivist perspective whilst retaining the attributes that characterise action research.

Organizational factors causing stress typically consist of poor positive feedback in reference to job performance, lack of autonomy and control, lack of participation in organizational decisions, ambiguity in job description, and conflicting role demands. Organizational factors that impact on individuals can cause frustration and disillusionment resulting from the differences between job realities and job expectations. Other organizational constraints include communication problems within interdisciplinary teams, role ambiguity, conflicting goals of the clinical staff and administration and the perceived lack of institutional support. High job turnover and absenteeism are also evident. For the critical group the response from the Aged Care Review Committee indicated to them that the expectation for nursing staff to be autonomous in their decision-making when assessing clients did not reflect true autonomy.

The specified learnings from this research were envisaged to be processes and strategies for employees to overcome the debilitating effects of stress leading to workplace burnout. Examining the nursing profession from a social perspective provides alternatives to medicalising workplace injuries and illnesses. The concerns for staff safety and wellness remain paramount as the States across Australia continue to amend legislation and develop best practice policies and procedures to safeguard employees. The study results will contribute to the knowledge base of the mental health discipline and extend the scientific 
body of nursing and midwifery knowledge. It will also inform future research priorities regarding mental health care provision utilizing an action research methodology.

The research study led to the development of a new understanding of the phenomena of interest in the study. Dealing with people who have serious mental health issues and/or illnesses is difficult and stressful for those who have no experience or training in the process of developing a therapeutic relationship and adequate assessment. The resulting stress may impact negatively on work satisfaction, perceptions of safety within the workplace and team functioning. Exploring the knowledge and skill deficits and other factors that contribute to the stress and identifying and implementing agreed actions helped to generate a "new" practice environment.

The new model of praxis resultant from this study can now be applied by the nurses when nursing consumers with mental health issues (Figure 1). The interpretation reflects the three main circles to represent the critical group (top), the training and education provided (right) and the flowcharts accepted by the organization (left). At the core of the model, these shared domains contribute to a reduction on the stress of the nurse participants, improvements in the occupational health, safety and wellness of staff, and improved patient outcomes.

There are solutions to the dilemma of the employee overcoming the debilitating effects of stress leading to workplace burnout. This includes the cooperation of managers, policy makers, academic researchers and government officials working collaboratively to reduce the impact of occupational stress. Through this collaborative process, changes can be effected to ensure the health of the nation improves and that relevant recognition is given to the fact that there is a significant threat to a healthy workforce. Examining the nursing profession from a social perspective provides alternatives to medicalising workplace injuries and illnesses.

\section{References}

Adami, M. F., \& Kiger. A. (2005). The use of triangulation for completeness purposes. Nurse Researcher, 12(4), 19-29.

Allen, D. (1990). Critical social theory and nursing education. In N. Greenleaf (Ed.), Curriculum revolution: Redefining the student-teacher relationship, (pp. 67-86). New York: National League for Nursing Press.

Annells, M., \& Whitehead, D. (2007). Analysing data in qualitative research. In Z. Schneider, D. Whitehead, D. Elliott, G. Lobiondo-Wood \& J. Haber (Eds.), Nursing \& midwifery research. Methods and appraisal for evidence-based practice, (3rd ed., pp. 138-155). Sydney: Elsevier.

Armstrong, P., \& Schulman, M. (1990). Financial strain and depression among farm operators: The role of perceived economic hardship and personal control. Rural Sociology, 55, 475-493.

Australian Institute of Health and Welfare (2005). (Catalogue No. HSE 40). Mental health services in Australia 2003-04. Canberra: AIHW.

Bailey, S. (1998). An exploration of critical care nurses' and doctors' attitudes towards psychiatric patients. Australian Journal of Advanced Nursing, 15, 8-14. 
Baskerville, R. (1999). Investigating information systems with action research. Communications of the Association for Information Systems, 2(19), 1-23. Accessed 7 November 2007 from http://www.cis.gsu.edu/ rbaskerv/CAIS_2_19/CAIS_2_19.html

Baskerville, R., \& Lee, A. S. (1999). Distinctions among different types of generalizing in information systems research. In L. Ngwenyama, M. Introna, M. Myers \& J. I. DeGross (Eds.), New information technologies in organizational processes: field studies and theoretical reflections on the future of work. (pp. 49-65). New York: Kluwer.

Beeson, P., \& Johnson, D. (1987). A panel study of change (1981-1986) in rural mental health status. Effects of the rural crisis. Paper presented at the National Institute of Mental Health Conference on Mental Health Statistics, Denver, CO.

Benveniste, K. A., Hibbert, P. D., \& Runciman, W. B. (2005). Violence in health care: The contribution of the Australian Patient Safety Foundation to incident monitoring and analysis. Medical Journal of Australia, 183(7), 348-351.

Bond, S., Barker, P., Pearson, P., \& Proctor, S. (1996). Forging links between academe and practice through research. Nursing Standard, 10(27), 43-45.

Borland, M. (2000). Australia's most wanted: the remote area nurse. Nursing Review, 5(3), 18.

Branco, E., Chambers, I., Fallon, A., Fraser, J., \& Howlett, S. (1981). Management of burnout in the helping professions, Australian Social Work, 34(3), 27-31.

Brent, K. (1993). Perspectives on critical and feminist theory in developing nursing praxis. Journal of Professional Nursing, 9(5), 296-303.

Broadbent, M., Jarman, H., \& Berk, M. (2004). Emergency department mental health triage scales improve outcomes. Journal of Evaluation in Clinical Practice, 10(1), 57-62.

Bryant, L. (1992). Social aspects of the farm financial crisis. In F. M. Vanclay, G.A. Lawrence, \& B. Furze (Eds.), Agriculture, environment \& society: Contemporary issues for Australia, (pp. 157-171). South Melbourne: MacMillan.

Burns, N., \& Grove, S. (1993). The practice of nursing research. Conduct, critique \& utilization. (2nd ed.). Philadelphia: W. B.Saunders Company.

Bushy, A. (2004). Creating nursing research opportunities in rural healthcare facilities. Journal of Nursing Care Quality Assurance, 19(2), 162-168.

Buunk, B. P., \& Schaufeli, W. B. (1993). Burnout: A perspective from social comparison theory. In W. B. Schaufeli, C. Maslach \& T. Marek (Eds.), Professional burnout: Recent developments in theory and research, (pp. 53-69). Washington, DC: Taylor \& Francis.

Campbell, J. E. (1985). A role for nurse psychotherapists: Primary prevention counselling for general hospital staffs. Perspectives in Psychiatric Care, 23(3), 85-90.

Carlin, L., \& Farnell, L. (1985). The stress audit-An avenue for individual and organizational change. Work and People, 11(1), 21-27.

Carr, W., \& Kemmis, S. (1986). Becoming critical: Knowing through action research. London: Falmer Press.

Carr, W. \& Kemmis, S. (1990). Becoming critical: Education, knowledge and action research, Deakin University.

Carr, W. \& Kemmis, S. (1994). Becoming Critical: Education, knowledge and action research, Waurn Ponds: Deakin University. 
Caufield, N., Chang, D., Dollard, F., \& Elshaug, C. (2004). A review of occupational stress interventions in Australia. International Journal of Stress Management, 11(2), 149166.

Cherniss, C. (1982). Staff burnout. Job stress in the human services. Sage Studies in Community Mental Health 2. London: Sage Publications.

Clark, D. E., Brown, A.M., Hughes, L., \& Motluk, L. (2006). Education to improve the triage of mental health patients in general hospital emergency departments. Accident and Emergency Nursing, 14(4), 210-218.

Cleary, M., \& Walter, G. (2006). Educating mental health nurses in clinical settings. Contemporary Nurse, 21(1), 153-159.

Clinton, M., \& Hazelton, M. (2000). Scoping the prospects of Australian mental health nursing. Australian and New Zealand Journal of Mental Health Nursing, 9(4), 159_ 165.

Cohen, L. H., McGowen, J., Fookskas, S., \& Rose, S. (1984). Positive life events and social supports and the relationship between life stress and psychological disorder. American Journal of Community Psychology, 12, 564-587.

Cook, S., \& Fontaine, K. (1991). Essentials of mental health nursing. (2nd ed.).Redwood City: Addison-Wesley Nursing.

Constantini, A., Solano, I., DiNapoli, R., \& Bosco, A. (1997). Relationship between hardiness and risk of burnout in a sample of 92 nurses working in oncology and AIDS wards. Psychotherapy and Psychosomatics, 66, 78-82.

Cotton, P., \& Hart, P.M. (2003). Occupational wellbeing and performance: A review of organisational health research. Australian Psychologist, 38(2), 118-127.

Coup, A., \& Schneider, Z. (2007). Ethical and legal issues in research. In Z. Schneider, D. Whitehead, D. Elliott, G. Lobiondo-Wood \& J. Haber (Eds.), Nursing \& midwifery research. Methods and appraisal for evidence-based practice, (3rd ed., pp. 80-101). Sydney. Elsevier.

Croll, N. (1997). Community mental health policy. In H. Gardner (Ed.), The politics of health: The Australian experience, (2nd ed., pp. 292-299). Melbourne: Churchill Livingstone.

Cronenwett, L. R., \& Redman, R. (2003). Partners in action. Nursing education and nursing practice. Nurse Educator, 28(4), 153-155.

Cutcliffe, J. R., \& Goward, P. (2000). Mental health nurses and qualitative research methods: a mutual attraction? Journal of Advanced Nursing, 31, 590-598.

Department of Human Services, Victoria. (2007). Mental health and Victoria's Emergency Departments [online]. Accessed 6 October 2007 from http://www.health.vic.gov.au/emergency/mental.htm

Descamp, K., \& Thomas, C. (1993). Buffering nursing stress through play at work. Western Journal of Nursing Research, 15, 619-627.

Drury, V., Francis, K., \& Delhunty, G. (2005). The lived experience of rural mental health nurses. Online Journal of Rural Nursing and Health Care, 5(1), 19-27. Accessed 4 May 2008 from http://www.rno.org/journal/index.php/onlinejournal/issue/view/15

Duckett, S. (2005). Health workforce design for the 21st century. Australian Health Review, 29(2), 201-210. 
Duquette, A., Kerouac, S., Sandhu, B. K., \& Beaudet, L. (1994). Burnout: a review of empirical knowledge. Issues in Mental Health Nursing, 15, 337-358.

Ellis, N. (1995). The organizational approach to stress management. In P. Cotton (Ed.), Psychological health in the workplace: Understanding and managing occupational stress, (pp. 31-50). Melbourne: Australian Psychological Society.

Ezzy, D. (2006). The research process. In M. Walter (Ed.), Social research methods an Australian perspective, (pp. 29-52). South Melbourne: Oxford University Press.

Falk-Rafael, A. (2005). Advanced nursing theory through theory-guided practice. The emergence of a critical caring perspective. Advances in Nursing Science, 28(1), 4956.

Francis, K., \& Chapman, Y. (2008). Rural and remote community nursing. In D. Kralik \& A. van Loon (Eds.), Community nursing in Australia, (pp. 148-158). Oxford: Blackwell Publishing.

Fraser, C., Judd, F., Jackson, H., Murray, G., Humphreys, J., \& Hodgins, G. A. (2002). Does one size really fit all? Why the mental health of rural Australians requires further research. Australian Journal of Rural Health, 10(6), 288-295.

Freire, P. (1990). Education for critical consciousness.(Trans. M. Ramos). New York: Continuum.

Freudenberger, H. J. (1989). Burnout: Past, present and future concern. Loss and Grief Care, $3(1-2), 1-10$.

Gerber, R. (1999). The role of theory in social and health research. In V. Minichiello, G. Sullivan, K. Greenwood \& R. Axford, (Eds.), Handbook for research methods in health sciences, (pp. 16-33). South Melbourne: Addison Wesley Longman.

Gerber, R, \& Moyle, W. (2004). The role of theory in health research. In V. Minichiello, G. Sullivan, K. Greenwood \& R. Axford (Eds.), Handbook of research methods for nursing and health science, (2nd ed., pp. 34-58). Frenchs Forest: Pearson Education Australia.

Gibb, H. (2003). Rural community mental health nursing: A grounded theory account of sole practice. International Journal of Mental Health Nursing, 12(4), 243-250.

Gillespie, M. \& Melby, V. (2003). Burnout among nursing staff in accident and emergency and acute medicine: a comparative study. Journal of Clinical Nursing, 12, 842-851.

Gladding, S.T. (1992). Counselling: A comprehensive profession. New York: Merrill.

Glasberg, A-L., Norberg, A., \& Söderberg, A. (2007). Sources of burnout among healthcare employees as perceived by managers. Journal of Advanced Nursing, 60, pp. 10-19.

Glasson, J. (1996). The public image and the mentally ill and community care. British Journal of Nursing, 5(10), 615-617.

Greenwood, J. (1994). Action research: a few details, a caution and something new. Journal of Advanced Nursing, 20, 13-18.

Habermas, J. (1971). Knowledge and human interests. (Trans. J. J. Shapiro). Boston: Beacon Press.

Habermas, J. (1984).The theory of communicative action. Vol. 1. Reason and rationalization of society. (Trans. T. McCarthy). Boston: Beacon Press.

Halcomb, E., Davidson, P., Daly, J., Griffiths, R., Yallop, J., \& Tofler, G. (2005). Nursing in Australian general practice: directions and perspectives. Australian Health Review, 29(2), 156-166. 
Happell, B., \& Plantania-Phung, C. (2005). Mental health issues within the general health care system: the challenge for nursing education in Australia. Nurse Education Today, 25(6), 465-471.

Hart, E. \& Bond, M. (1995). Action research for health and social care. A guide to practice. Buckingham: Open University Press.

Hays, R., \& Beaton, N. (2004). Rural hospital medicine. In D. Wilkinson, R. Hays, R. Strasser \& P. Worley (Eds.), The handbook of rural medicine in Australia, (pp. 128-135). South Melbourne: Oxford University Press.

Heard, R., \& Harris, L. M. (2004). Experimental, quasi-experimental and correlational quantitative research designs. In V. Minichiello, G. Sullivan, K. Greenwood \& R. Axford (Eds.), Handbook of research methods for nursing and health science, (2nd ed., pp.124-150). Frenchs Forest: Pearson Education Australia.

Heath, P., Duncan, J., Lowe, E., Macri, S., Ramsay, J., Selby Smith, C., \& Watts, R. (2002). Our duty of care: National review of nursing education. (Catalogue No. DEST6880 HERCO 2A). Canberra: Commonwealth Department of Education, Science \& Training. Accessed 24 April 2007 from

http://www.dest.gov.au/archive/highered/nursing/pubs/duty_of_care/default. html

Hegney, D., Pearson, A., \& McCarthy, A. (1997). The role and function of the rural nurse in Australia. Canberra: Royal College of Nursing Australia.

Hehir, B. (2006). Is it all in the mind? [Reflections]. Nursing Standard, 21(7), 28-29.

Holter, I. M., \& Schwartz-Barcott, D. (1993). Action research: what is it? How has it been used and how can it be used in nursing? Journal of Advanced Nursing, 18, 298-304.

Hugo, G. (2001). What is really happening in regional and rural populations? In M. F. Rogers \& Y. M. J. Collins (Eds.), The future of Australia's country towns, (pp. 5771). Bendigo: La Trobe University.

Humphreys, J., \& Rolley, F. (1991). Health and health care in rural Australia. Armidale: University of New England.

Jackson, D., \& Borbasi, S. (2008). Qualitative research: the whole picture. In S. Borbasi, D. Jackson \& R. Langford (Eds.), Navigating the maze of nursing research. An interactive learning adventure, (2nd ed., pp.151-177). Sydney: Elsevier.

Johnson, D., \& Preston, B. (2001). (Catalogue No. DETYA 6761HERCO1A).An overview of issues in nursing education. Canberra: Department of Education, Training and Youth Affairs. Accessed 23 June, 2007 from http://www.dest.gov.au/archive/highered/eippubs/eip01_12/default.htm

Jones, S. R. (2002). (Re)writing the word: Methodological strategies and issues in qualitative research. Journal of College Student Development, 43, 461-473.

Joy, C. B., Adams, C. E., \& Rice, K. (1999, reprinted 2008). Crisis intervention for people with severe mental illnesses. Cochrane Database of Systematic Reviews 2008, (4). Article CD001087.

Judd, F., \& Humphreys, J. (2001). Mental health issues for rural and remote Australia. Australian Journal of Rural Health, 9(5), 254-258.

Kemmis, S., \& McTaggart, R. (1982). The action research planner. (2nd ed.). Deakin University.

Kemmis, S. \& McTaggart, R. (Eds.). (1988). The action research planner (3rd ed.). Deakin University. 
Kennedy, P., \& Grey, N. (1997). High pressure areas. Nursing Times, 93(29), 26-27.

Kenny, J. W. (2000). Women's 'inner-balance'; a comparison of stressors, personality traits and health problems by age groups. Journal of Advanced Nursing, 31, 639-650.

Kenny, A., \& Duckett, S. (2003). Educating for rural nursing practice. Journal of Advanced Nursing, 44, 613-622.

Kenny, A. \& Duckett, S. (2005). An online study of Australian enrolled nurse conversion. Journal of Advanced Nursing, 49, 423-431.

Kerrison, S. A., \& Chapman, R. (2007). What general emergency nurses want to know about mental health patients presenting to their emergency department. Accident and Emergency Nursing, 15(1), 48-55.

King, C. (2001). Severe mental illness: Managing the boundary of a CMHT. Journal of Mental Health, 10(1), 75-86.

Lachman, V. (1996). Stress and self-care revisited. A literature review. Holistic Nursing Practice, 10(2), 1-12.

Lambert, B, (1995). Give your company a check-up. Personnel Journal, 74(9), 143-145.

Lancaster, J. (1982). Change theory: An essential aspect of nursing practice. In J. Lancaster \& W. Lancaster (Eds.), Concepts for advanced nursing practice: The nurse as change agent, (pp. 5-23). St.Louis: C.V. Mosby Company.

Lancaster, J., \& Lancaster, W. (1982). Theoretical foundations for change. In J. Lancaster \& W. Lancaster (Eds.), Concepts for advanced nursing practice: The nurse as change agent, (pp. 1-4). St.Louis: C.V. Mosby Company.

Lauder, W., Reynolds, W., Reilly, V., \& Angus, N. (2001). The role of the district nurses in caring for people with mental health problems who live in rural settings. Journal of Clinical Nursing, 10(3), 337-344.

Lauri, S. (1982). Development of nursing process through action research. Journal of Advanced Nursing, 7, 301-307.

Lawrence, G. (1987). Capitalism and the countryside: the rural crisis in Australia. Sydney: Pluto.

Lazarus, R. S., \& Folkman, S. (1984). Stress, appraisal and coping. New York: Springer.

Lewis, D. J., \& Robinson, J. A. (1992). ICU nurses' coping measures: Response to work related stressors. Critical Care Nurse, 12(2), 18-23.

Light, K. (1981). Cardiovascular responses to effortful active coping: Implications for the role of stress in hypertension development. Psychophysiology, 18, 216-225.

Lindsey, E., Stajduhar, K., \& McGuinness, L. (2001). Examining the process of community development. Journal of Advanced Nursing, 33, 828-835.

Llewellyn, G. Sullivan, G., \& Minichiello, V. (2004). Sampling in qualitative research. In V. Minichiello, G. Sullivan, K. Greenwood \& R. Axford (Eds.), Handbook of research methods for nursing and health science, (2nd ed., pp. 210-241 ). Frenchs Forest: Pearson Education Australia.

Mahnken, J. E. (2001). Rural nursing and health care reforms: building a social model of health. Rural and Remote Health, 1. Accessed 15 May 2008 from http://www.regional.org.au/au/rrh/2001/011214_104.htm

Malach-Pines, A. (2000). Nurses' burnout, an existential psychodynamic perspective. Journal of Psychosocial Nursing \& Mental Health Services, 38(2), 23-31.

Maslach, C. (1976). Burnout, anxiety, stress and coping. Human Behavior, 5(9), 16-22. 
Maslach, C. (1979). The burnout syndrome in patient care. In C. Garfield (Ed.), Stress and survival: The emotional realities of life-threatening illness, (pp. 111-120). St. Louis: Mosby.

Maslach, C. (1981). Burnout: A social psychological analysis. In J. W. Jones (Ed.), The burnout syndrome, (pp. 30-50). Park Ridge: London House Press.

Maslach, C. (1982). Burnout: the cost of caring. New York: Prentice Hall.

Maslach, C. (1986). Stress, burnout and alcoholism. In R. R. Kilburg, P. E. Nathan \& R. W. Thoreson (Eds.), Professionals in distress: Issues, syndromes and solutions in psychology, (pp. 53-76). Washington, DC: American Psychological Association.

Maslach, C., \& Jackson, S. E. (1981). Maslach Burnout Inventory. Palo Alto: Consulting Psychologists Press.

Maslach, C., \& Jackson, S. E. (1982). Burnout in health professionals: A social psychological analysis. In G. Sanders \& J. Suls (Eds.), Social psychology of health and illness, (pp. 227-231). Hillsdale: Erlbaum.

Maude, P., \& Warelow, P. (2011). 'Wise Men, Devils and fools': The History of Mental Illness and its Treatment. In Edward, K-L., Munro, I., Robins, A., Welch, A. (Eds). Mental Health Nursing Dimensions of Praxis. Melbourne, Oxford.

McCaugherty, D. (1991). The use of a teaching model to promote reflection and the experiential integration of theory and practice in first-year student nurses: an action research study. Journal of Advanced Nursing, 16, 534-543.

McLaren, S., Jude, B., Hopes, L., \& Sherritt, T. (2001). Sense of belonging, stress and depression in rural-urban communities. International Journal of Rural Psychology, 2(7). $\quad$ Accessed $21 \quad$ September 2007 from http:// www.ruralpsych.com/Members/RefereedArticles/RR-McLaren-JudeHopes-Sherritt.htm

Melamed, S., Shirom, A., Toker, S., Berliner, S., \& Shapira, I. (2006). Burnout and risk of cardiovascular disease: Evidence, possible causal paths, and promising research directions. Psychological Bulletin, 132(3), 327-353.

Meyer, J. (1995). Stages in the process: a personal account. Nurse Researcher, 2(3), 24-37.

Mugo, F.W. (2003). Sampling in research. [online] Accessed 21 July 2007 from http://trochim.human.cornell.edu/tutorial/mugo/tutorial.htm

Murphy, L. R. (1996). Stress management in work settings: A critical review of the health effects. American Journal of Health Promotion, 11(2), 112-135.

Murray, R. B., \& Huelskoetter, M. M. W. (1991). Psychiatric mental health nursing. (3rd ed.). Norwalk, Conn.: Appleton \& Lange.

National Health and Medical Research Council. (2007). National statement on ethical conduct in human research [online]. Accessed 22 October 2007 from http://www.nhmrc.gov.au/publications/synopses/e72syn.htm

New South Wales Mental Health Act. (1990). Accessed 23 October 2011 from http://www.health.wa.gov.au/mhareview/resources/legislation/nsw_mental_he alth_act_1990.pdf

New South Wales Occupational Health and Safety Act. (2004). Accessed 23 October 2007 from http:/ / www.legislation.nsw.gov.au/fullhtml/inforce/act+40+2000+FIRST+0+N 
Owens, J., Stein, I., \& Chenoweth, L. (1999). Action research. In V. Minichiello, G. Sullivan, K. Greenwood \& R. Axford (Eds.), Handbook for research methods in health sciences, (pp. 247-270). Frenchs Forest: Addison Wesley Longman.

Pante, M. (1999). Thrown in at the deep end: Psychiatric nurses' attitudes to educational preparation for clinical practice. Melbourne: Health and Community Services Union.

Patton, M. Q. (1990). Qualitative evaluation and research methods. Newbury Park: Sage.

Pearce, J. (1981). Bringing some clarity to role ambiguity research. Academy of Management Review, 6, 665-674.

Pearson, A. (1989). Action research methodology. Paper presented at the Quantitative and Qualitative Methods Workshop, Melbourne University, 13-15 July.

Pearson, A. (1992). Nursing at Burford. A story of change. Harrow: Scutari Press.

Perkin, R., Young, T., Freier, M., Allen, J., \& Orr, D. (1997). Stress and distress in paediatric nurses: Lessons from Baby K. American Journal of Critical Care, 6(3), 225-232.

Pines, A. M., \& Aronson, E. (1981). Burnout. New York: Free Press.

Pines, A. M., \& Maslach, C. (1978). Characteristics of staff burnout in a mental health setting. Hospital and Community Psychiatry, 29, 233-237.

Pinikahana, J., \& Happell, B. (2004). Stress, burnout and job satisfaction in rural psychiatric nurses: A Victorian study. Australian Journal of Rural Health, 12(3), 120-125.

Polit, D. \& Hungler, B. (1991). Nursing research. Principles and methods. (4th ed.). Philadelphia: J. B. Lippincott Company.

Pompili, M., Rinaldi, G., Lester, D., Girardi, P., Ruberto, A., \& Tatarelli, R. (2006). Hopelessness and suicide risk emerge in psychiatric nurses suffering burnout and using specific defence mechanisms. Archives of Psychiatric Nursing, 20(3), 135-143.

Productivity Commission. (2005). Australia's health workforce. Research report. Melbourne: Productivity Commission.

Quevillon, R. P., \& Trenerry, M. R. (1983) Research on rural depression: implications of social networks for theory and treatment. International Journal of Mental Health, $12,45-61$.

Reason, P. (1988). Human inquiry in action: Developments in new paradigm research. London: Sage Publications.

Rees, D., \& Cooper, C. (1992). The occupational stress indicator locus of control scale: Should this be regarded as a state rather than a trait measure? Work and Stress, 6, 45-48.

Rolfe, G. (1996). Going to extremes: action research, grounded practice and the theorypractice gap in nursing. Journal of Advanced Nursing, 24, 1315-1320.

Saines, J. C. (1999). Violence and aggression in A\&E: Recommendations for action. Accident and Emergency Nursing, 7(1), 8-12.

Schaefer, J. A., \& Moos, R. H. (1996). Effects of work stressors and work climate on longterm care staff's job morale and functioning. Research in Nursing and Health, 19, 63-73.

Schmitz, N., Neumann, W., \& Oppermann, R. (2000). Stress, burnout and locus of control in German nurses. International Journal of Nursing Studies, 37(2), 95-99.

Scopelliti, J., Judd, F., Grigg, M., Hodgins, G., Fraser, C., Hulbert, C., Endacott, R., \& Wood, A. (2004). Dual relationships in mental health practice: Issues for clinicians in rural settings. Australian and New Zealand Journal of Psychiatry, 38, (11-12), 953-959. 
Senate Community Affairs Reference Committee [SCARC]. (2002) The patient profession, time for action report on the inquiry into nursing. Canberra: Senate Community Affairs Reference Committee Secretariat.

Seng, J. S. (1998). Praxis as a conceptual framework for participatory research in nursing. Advances in Nursing Science, 20(4), 37-41.

Selye, H. (1956). The stress of life. New York: McGraw Hill.

Selye, H. (1974). Stress without distress. Philadelphia: Lippincott.

Selye, H. (1976). Further thoughts on "stress without distress." Medical Times, 104, 124-132.

Shaban, R. (2006). Paramedics' clinical judgment and mental health assessments in emergency contexts: Research, practice, and tools of the trade. Journal of Emergency Primary Health Care, 4(2), paper no. 990177. Accessed 21 October 2007 from http://www.jephc.com/full_article.cfm?content_id=375

Sharrock, J., \& Happell, B. (2002). The role of a psychiatric consultation liaison nurse in a general hospital: A case study approach. Australian Journal of Advanced Nursing, 20(1), 39-44.

Sheehan, J. (1996). Aspects of research methodology. Nurse Education Today, 6, 193-203.

Silverman, D. (2006). Interpreting qualitative data. (3rd Ed.). London: Sage Publications Ltd.

Simmons, S. (1995). From paradigm to method in interpretive action research. Journal of Advanced Nursing, 21, 837-844.

Simoni, P. S., \& Paterson, J. J. (1997). Hardiness, coping and burnout in the nursing workplace. Journal of Professional Nursing, 13(3), 178-185.

Snow, T. (2006).Taking the strain. Nursing Standard, 20(46), 16-17.

Stevens, P. (1989). A critical social reconceptualization of environment in nursing: implications for methodology. Advances in Nursing Science, 11(4), 56-58.

Stewart, E., McKenery, P., Rudd, N., \& Gavazzi, S. M. (1994). Family processes as mediators of depressive symptomatology among rural adolescents. Family Relations, 43, 3845.

Street, A. F. (2004). Action research. In V. Minichiello, G. Sullivan, K. Greenwood \& R. Axford (Eds.), Handbook of research methods for nursing and health science, (2nd ed., pp. 278-294). Frenchs Forest: Pearson Education Australia.

Stringer, E. T. (1996). Action research: A handbook for practitioners. Newbury Park: Sage Publications Inc.

Strong, K., Trickett, P., Titulaer, I., \& Bhatia, K. (1998). (Catalogue No. PHE 6). Health in rural and remote Australia. The first report of the Australian Institute of Health and Welfare on rural health.. Canberra: Australian Institute of Health and Welfare.

Susman, G. I., \& Evered, R.D. (1978). An assessment of the scientific merits of action research. Administrative Science Quarterly, 23, 582-603.

Taylor, C. (1993). Intershift report: oral communication using a quality assurance approach. Journal of Clinical Nursing, 2(5), 266-267.

The health Services Advisory committee. (1997). Violence in the education sector (Education Service Advisory Committee, HSE Books, 1997, ISBN 0717612937

Titchen, A., \& Binnie, A. (1993). Research partnerships: Collaborative action research in nursing. Journal of Advanced Nursing, 18, 858-865.

Tolley, K. (1995). Theory from practice: is this a reality? Journal of Advanced Nursing, 21, 184-190. 
Turnipseed, D. L. (1988). An integrated, interactive model of organizational climate, culture, and effectiveness. Leadership and Organizational Journal, 9, 17-21.

Turnipseed, D. (1994). An analysis of the influence of work environment variables and moderators on the burnout syndrome. Journal of Applied Psychology, 24(9), 782800.

Vanclay, F. (1994). A crisis in agricultural extension? Rural Society, 4(1). Accessed 20 September 2007 from http:/ / www.csu.edu.au/research/crsr/ruralsoc/v4n1p10.htm.

Victoria Mental Health Act. (1986).

Victoria Occupational Health and Safety Act. (2004).

Wadsworth, Y. (1997). Do it yourself social research. (2nd ed.). St Leonards: Allen and Unwin.

Wallis, S. (1998). Changing practice through action research. Nurse Researcher, 6(2), 5-15.

Walter, M. (2006). Surveys and sampling. In M. Walter (Ed.), Social research methods an Australian perspective, (pp. 187-222). South Melbourne: Oxford University Press.

Whitehead, D. (2007). An overview of research theory and process. In Z. Schneider, D. Whitehead, D. Elliott, G. Lobiondo-Wood \& J. Haber (Eds.), Nursing \& midwifery research. Methods and appraisal for evidence-based practice, (3rd ed., pp. 20-32). Sydney: Elsevier.

Whitehead, D., \& Annells, M. (2007). Sampling data and data collection in qualitative research. In Z. Schneider, D. Whitehead, D. Elliott, G. Lobiondo-Wood \& J. Haber (Eds.), Nursing \& midwifery research. Methods and appraisal for evidence-based practice, (3rd ed., pp. 122-137). Sydney: Elsevier.

Whitehead, D., \& Elliott, D. (2007). Mixed methods research. In Z. Schneider, D. Whitehead, D. Elliott, G. Lobiondo-Wood \& J. Haber (Eds.), Nursing \& midwifery research. Methods and appraisal for evidence-based practice, (3rd ed., pp. 248-267). Sydney: Elsevier.

Willis, K. (2006). Analysing qualitative data. In M. Walter (Ed.), Social research methods an Australian perspective, (pp. 256-279). South Melbourne: Oxford University Press.

Wright, S. (1991). Tameside Nursing Development Unit: a decade of success. Nursing Standard, 6(7), 49-56.

Wynaden, D., O'Connell, B., McGowan, S., \& Popescu, A. (2000). The educational needs of nurses' [sic] in the area of mental health. The Australian Electronic Journal of Nursing Education, 6(2), no pagination. Accessed 24 April 2006 from http://www.scu.edu.au/schools/nhcp/aejne/archive/vol6-1/wynadend.html

Young, K. (2011). Child and Adolescent Mental Health. In Edward, K-L., Munro, I., Robins, A., Welch, A. (Eds). Mental Health Nursing Dimensions of Praxis. Melbourne, Oxford. 


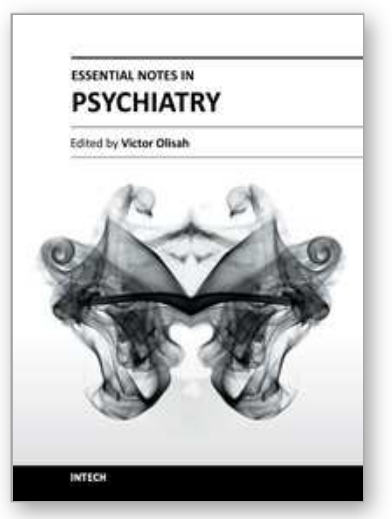

\author{
Essential Notes in Psychiatry \\ Edited by Dr. Victor Olisah
}

ISBN 978-953-51-0574-9

Hard cover, 580 pages

Publisher InTech

Published online 27, April, 2012

Published in print edition April, 2012

Psychiatry is one of the major specialties of medicine, and is concerned with the study and treatment of mental disorders. In recent times the field is growing with the discovery of effective therapies and interventions that alleviate suffering in people with mental disorders. This book of psychiatry is concise and clearly written so that it is usable for doctors in training, students and clinicians dealing with psychiatric illness in everyday practice. The book is a primer for those beginning to learn about emotional disorders and psychosocial consequences of severe physical and psychological trauma; and violence. Emphasis is placed on effective therapies and interventions for selected conditions such as dementia and suicide among others and the consequences of stress in the workplace. The book also highlights important causes of mental disorders in children.

\title{
How to reference
}

In order to correctly reference this scholarly work, feel free to copy and paste the following:

Eileen Petrie (2012). Reducing Stress in Mental Health Practitioners - Becoming Change Agents in Practice Through Action Research, Essential Notes in Psychiatry, Dr. Victor Olisah (Ed.), ISBN: 978-953-51-0574-9, InTech, Available from: http://www.intechopen.com/books/essential-notes-in-psychiatry/reducing-stress-inmental-health-practitioners-becoming-change-agents-in-practice-through-action-r

\section{INTECH}

open science | open minds

\section{InTech Europe}

University Campus STeP Ri

Slavka Krautzeka 83/A

51000 Rijeka, Croatia

Phone: +385 (51) 770447

Fax: +385 (51) 686166

www.intechopen.com

\section{InTech China}

Unit 405, Office Block, Hotel Equatorial Shanghai

No.65, Yan An Road (West), Shanghai, 200040, China

中国上海市延安西路65号上海国际贵都大饭店办公楼 405 单元

Phone: +86-21-62489820

Fax: +86-21-62489821 
(C) 2012 The Author(s). Licensee IntechOpen. This is an open access article distributed under the terms of the Creative Commons Attribution 3.0 License, which permits unrestricted use, distribution, and reproduction in any medium, provided the original work is properly cited. 